EXTENDED REPORT

\title{
Impact of pregnancy on health related quality of life evaluated prospectively in pregnant women with rheumatic diseases by the SF-36 health survey
}

\author{
F Förger, M Østensen, A Schumacher, P M Villiger
}

Ann Rheum Dis 2005;64:1494-1499. doi: 10.1136/ard.2004.033019

See end of article for authors' affiliations

Correspondence to:

ProfessorMonikaØstensen, Department of

Rheumatology and Clinical Immunology and

Allergology, University Hospital, CH-3010 Bern,

Switzerland; monika.

oestensen@insel.ch

Accepted 14 March 2005

Published Online First

18 March 2005
Objective: To gain insight into patient experience of the disease course and health related quality of life during and after pregnancy in women with rheumatoid arthritis and ankylosing spondylitis.

Methods: 10 patients with rheumatoid arthritis, 10 patients with ankylosing spondylitis, and 29 age matched healthy pregnant controls were evaluated by the medical outcomes study short form 36 (SF-36) health survey once at each trimester and at 6, 12, and 24 weeks postpartum. A group of non-pregnant age matched female patients (40 rheumatoid arthritis, 16 ankylosing spondylitis) was studied for comparison.

Results: Impaired physical dimensions as well as increased bodily pain was observed in healthy women in late pregnancy. Patients with rheumatoid arthritis showed improved physical functioning scores in the second trimester and reduced pain in the third trimester. Among pregnant patients, those with ankylosing spondylitis suffered the greatest impairment of health related quality of life during pregnancy. In all patient groups the physical impairment in the third trimester was less pronounced than in healthy controls. Mental health scores remained stable even with persisting active disease during pregnancy, or with a postpartum flare.

Conclusions: Pregnancy reduced physical functioning in healthy women and patients, but had no impact on mental and emotional health, even at times of disease aggravation. The pregnancy experience documented in our patients may be helpful when counselling patients contemplating pregnancy.
$\mathrm{D}$ uring the progress of pregnancy hormonal and organ specific changes alter physical functioning and sometimes also mental wellbeing. As a consequence, the perception of quality of life may change. In healthy women, the negative aspects of bodily symptoms caused by pregnancy sometimes prevail. In women with chronic rheumatic disease the positive aspects of becoming a mother are more readily perceived. This is especially the case in rheumatic diseases that improve during pregnancy, such as rheumatoid arthritis. ${ }^{1}$ Even in women with a disease that remains active during pregnancy, like ankylosing spondylitis, ${ }^{2}$ the fulfilment of a desire for children can mitigate bodily symptoms. ${ }^{3}$

The clinical effect of pregnancy on rheumatic diseases is usually measured by disease specific instruments. However, these measures may not reflect the aspects that are most important to the patients in their everyday life. The medical outcomes study short form 36 item health survey (SF-36) is a generic instrument for assessing health related quality of life that has been shown to be both valid and acceptable in a normal healthy population and reliable across diverse patient groups. ${ }^{4-6}$ A generic measurement allows for comparison with other diseases and general populations, as it is not specific to any age, disease, or treatment group. The SF-36 is suitable for self administration and has the advantage of describing the impact of the disease in terms of patient centred outcome rather than the disease centred outcome perceived by clinicians

The present prospective study had the aim of disclosing not only the physical impact of pregnancy on rheumatic disease but also of assessing psychological aspects such as role functioning, vitality, anxiety, and depression. We hypothesised that pregnant women with rheumatic disease and a desire for children would have equal or even greater mental wellbeing than healthy pregnant women, but show more physical impairment during pregnancy. As both rheumatoid arthritis and ankylosing spondylitis most often flare within six months after delivery, we expected a decrease in physical and mental scores postpartum in the patients but not in healthy women. In a previous study of pregnant patients with rheumatic disease, we have noted differences between the physician's global assessment and the self assessment of the patient in regard to disease activity. ${ }^{7}$ It seemed therefore of interest to compare the SF-36 with other clinical disease assessments and to evaluate how the patients experience pregnancy and the postpartum period.

\section{METHODS}

\section{Patients and controls}

The study was approved by the ethical committee of the University of Berne. Included in the study were 20 pregnant patients (10 with rheumatoid arthritis and 10 with ankylosing spondylitis) fulfilling the American College of Rheumatology ${ }^{8}$ or the modified New York criteria9 respectively. We further investigated 29 age matched healthy pregnant women and a group of non-pregnant age matched female patients (40 with rheumatoid arthritis, 16 with ankylosing spondylitis) to get the background data of a chronic inflammatory disease.

Clinical examination and evaluation of the disease specific as well as the generic measurement were carried out at the following time points: once at the first trimester (between gestational weeks 9 and 11), once at the second trimester (between weeks 20 and 22), once at the third trimester

Abbreviations: BASDAl, Bath ankylosing spondylitis activity index; NSAID, non-steroidal anti-inflammatory drug; RADAl, rheumatoid arthritis disease activity index; SF-36, short form 36 item general health survey 
Table 1 Clinical characteristics and drug treatment of the study population

\begin{tabular}{|c|c|c|c|c|c|}
\hline & Healthy pregn & RA pregn & RA non-pregn & AS pregn & AS non-pregn \\
\hline$n$ & 29 & 10 & 40 & 10 & 16 \\
\hline Age (years) & 31 (20 to 39$)$ & 29 (23 to 35$)$ & 34 (20 to 40$)$ & 31 (22 to 37 ) & 33 (19 to 41$)$ \\
\hline \multicolumn{6}{|l|}{ Disease duration } \\
\hline \multicolumn{6}{|l|}{ Parity* } \\
\hline 0 & 18 & 7 & 18 & 6 & 7 \\
\hline 1 & 8 & 3 & 10 & 4 & 2 \\
\hline 2 & 3 & 0 & 9 & 0 & 5 \\
\hline 3 & 0 & 0 & 3 & 0 & 2 \\
\hline \multicolumn{6}{|l|}{ On NSAID } \\
\hline Non-pregnant, & - & - & $33(83 \%)$ & - & $13(81 \%)$ \\
\hline During pregnancy & - & $2(20 \%)$ & - & $4(40 \%)$ & - \\
\hline Postpartum & - & $4(40 \%)$ & - & $7(70 \%)$ & - \\
\hline \multicolumn{6}{|l|}{ On prednisone† } \\
\hline Non-pregnant & - & - & $22(55 \%)$ & - & $4(25 \%)$ \\
\hline During pregnancy & - & $2(20 \%)$ & - & $0(0 \%)$ & - \\
\hline Postpartum & - & $3(30 \%)$ & - & $1(1 \%)$ & - \\
\hline \multicolumn{6}{|l|}{ On DMARD } \\
\hline Non-pregnant & - & - & $35(88 \%)$ & - & $7(44 \%)$ \\
\hline During pregnancy & - & $3(30 \%)$ & - & $0(0 \%)$ & - \\
\hline Postpartum & - & $6(60 \%)$ & - & $0(0 \%)$ & - \\
\hline $\begin{array}{l}\text { Values are } \mathrm{n}, \mathrm{n}(\% \\
{ }^{*} \text { Parity, number of } \\
\text { †Prednisone }<10 \\
\text { AS, ankylosing spo } \\
\text { NSAID, non-steroic }\end{array}$ & $\begin{array}{l}\text { mean (range). } \\
\text { idren born. } \\
\text { per day. } \\
\text { ylitis; DMARD, di } \\
\text { anti-inflammator }\end{array}$ & se modifying a & ntirheumatic dr & $\begin{array}{l}\text { number; non-p } \\
\text { toid arthritis. }\end{array}$ & regn, non-pregnant; \\
\hline
\end{tabular}

(between weeks 30 and 34), and once each at 6, 12, and 24 weeks postpartum.

Drugs allowed during pregnancy were non-steroidal antiinflammatory drugs (NSAIDs) until week 32 of gestation, prednisone $(<10 \mathrm{mg})$, antimalarial agents, and sulfasalazine.

\section{Measurement of disease activity and health related quality of life}

Clinical disease activity was monitored by physical examination and by validated instruments for rheumatoid arthritis and ankylosing spondylitis. Patients with rheumatoid arthritis were assessed by the rheumatoid arthritis disease activity index (RADAI). ${ }^{10}$ Patients with ankylosing spondylitis were assessed by the Bath ankylosing spondylitis activity index (BASDAI). ${ }^{11}$

Health related quality of life was measured using the German version of the SF-36. ${ }^{12}$ The SF-36 assesses the following eight dimensions: physical functioning, role limitation from physical health problems, bodily pain, general health, vitality, social functioning, role limitation from emotional health problems, and mental health. The score was declared invalid when there was no response to more than half its items. Raw score responses on the SF-36 were converted to a 100 point scale in which a higher number reflects a better health related functional status. ${ }^{13}$

\section{Statistical analysis}

For each scale of the SF-36 we computed median (range) and mean (SD). We applied the unpaired Mann-Whitney U test to compare the SF-36 scores between the study groups. To analyse the longitudinal changes of each SF-36 dimension we used the Wilcoxon test for paired samples. Bonferroni adjustment was carried out in relation to the number of study groups and the number of time points. Owing to the small numbers, prepregnancy visits were excluded. A value of $\mathrm{p}<0.05$ after Bonferroni correction was considered significant-that is, $\mathrm{p}<0.02$ in the comparison between the study groups and $p<0.01$ in the analysis of longitudinal changes. The associations between physical functioning scale and the disease specific measures were analysed using the Spearman's rank correlation.

\section{RESULTS}

\section{Patient characteristics}

Table 1 shows characteristics and drug treatment of the study population. All patients and healthy women included were of white origin and none of them belonged to a low income group.

The disease activity measured by the RADAI showed that seven rheumatoid patients improved during pregnancy and six flared in the postpartum period. According to the BASDAI scores, four patients with ankylosing spondylitis experienced clinical improvement during pregnancy and six remained active.

\section{Health related quality of life before, during, and after pregnancy}

The means and standard deviations of each SF-36 dimension are provided in table 2 for all study groups and the different time points. The physical functioning scores correlated significantly with both the RADAI $(r=-0.801, \mathrm{p}<0.01)$ and the BASDAI $(r=-0.640, \mathrm{p}<0.01)$. The mental health scores remained stable throughout the observation period in all patients and controls.

\section{Healthy pregnant women}

The 29 healthy women had a reduced health related quality of life during pregnancy, mainly because of progressive physical impairment (fig 1A), with a pronounced decrease in the physical functioning scores from the first to the second trimester $(p=0.006)$ and from the second to the third trimester $(\mathrm{p}<0.001)$. Healthy women experienced increased pain in late pregnancy (fig 2A). After delivery, the physical functioning scores (fig lA) recovered gradually $(p<0.001)$.

\section{Rheumatoid arthritis}

During pregnancy, patients with rheumatoid arthritis had improved scores for physical functioning and bodily pain. 


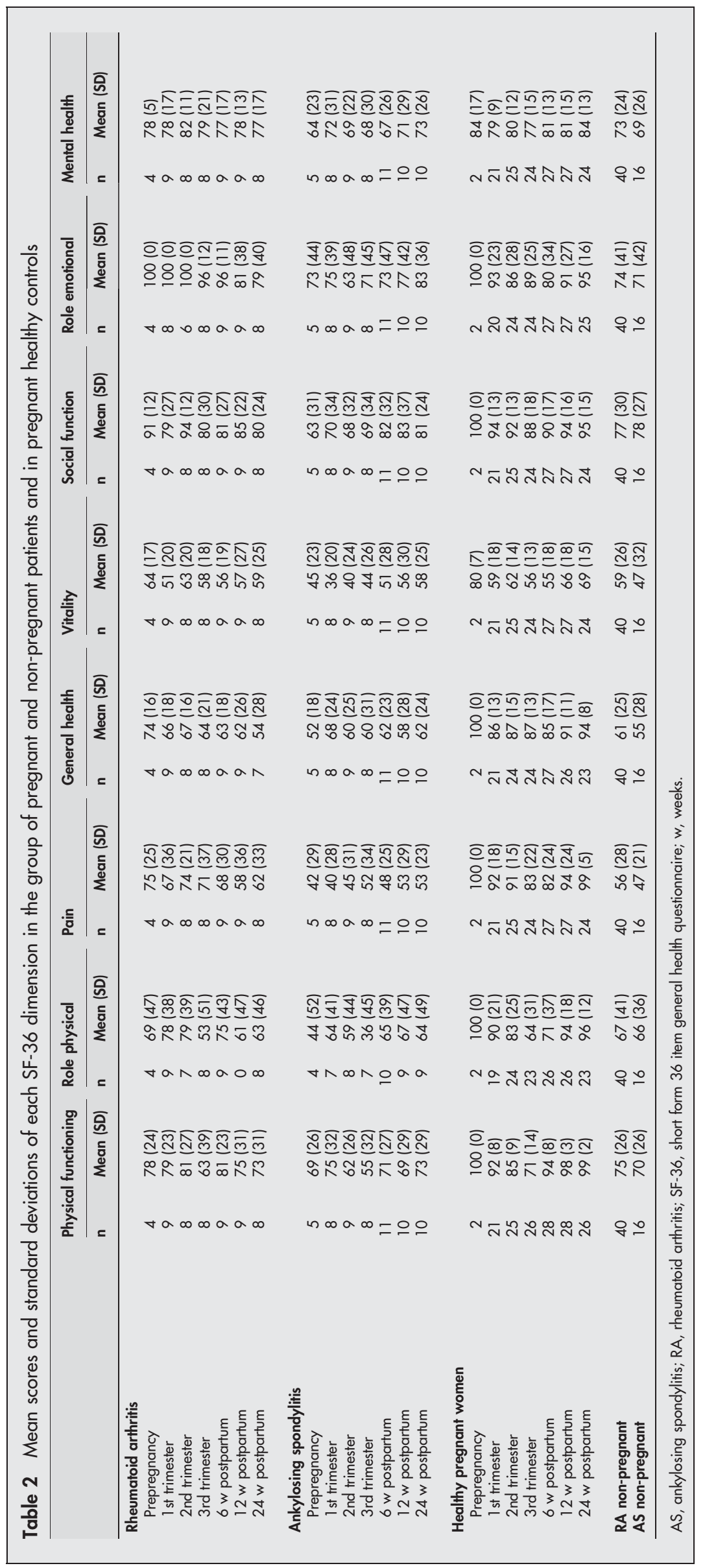



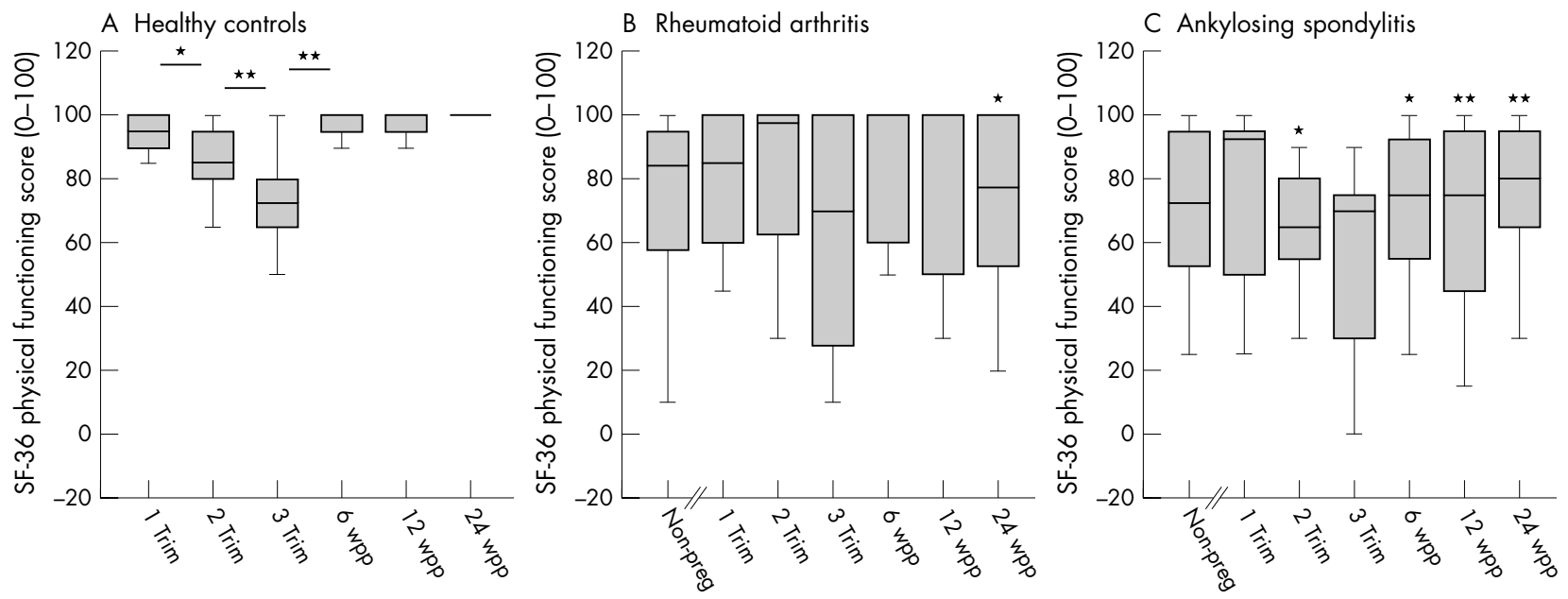

Figure 1 Short form 36 item general health survey (SF-36) physical functioning scores during and after pregnancy in healthy controls (A) and in patients with rheumatoid arthritis (B) and ankylosing spondylitis (C). SF-36 scores range from 0 to $100(0=$ worst score, $100=$ best scores). Boxes represent the 25th and 75th centiles; horizontal lines within boxes represent the medians; vertical lines above and below boxes represent the distribution beyond the 25 th to 75 th centile range. ${ }^{*} p<0.01$ (in healthy controls, significant difference between two time points; in patients with ankylosing spondylitis and rheumatoid arthritis, significant difference from healthy controls); ${ }^{* *} p<0.001$ (in healthy controls, significant difference between two time points, in ankylosing spondylitis patients, significant difference from healthy controls); non-preg = non-pregnant controls, 1 trim $=1 \mathrm{st}$ trimester, 2 trim $=2$ nd trimester, 3 trim $=3 r d$ trimester, $6 \mathrm{wpp}=6$ weeks postpartum, $12 \mathrm{wpp}=12$ weeks postpartum, $24 \mathrm{wpp}=24 \mathrm{weeks}$ postpartum.

Compared with non-pregnant patients, pregnant patients experienced significantly less pain $(p=0.028$, fig $2 \mathrm{~B})$. The postpartum deterioration in the disease at week 12 and 24 was reflected by significantly worse scores for bodily pain $(p=0.001, p<0.001)$ and for role physical $(p=0.019$, $\mathrm{p}=0.019$, data not shown) compared with healthy controls. Throughout the observation period the general health perception of rheumatoid patients (fig $3 \mathrm{~B}$ ) remained worse than in healthy women $(\mathrm{p}<0.001-0.007)$.

\section{Ankylosing spondylitis}

Throughout the observation period, most patients with ankylosing spondylitis had persistent disease with unchanged pain scores (fig 2C). Compared with healthy women, patients with ankylosing spondylitis had worse scores for bodily pain $(\mathrm{p}<0.001)$ and physical functioning $(p=0.007-0.001)$ during pregnancy and in the postpartum period. The general health perception remained significantly lower than in healthy controls $(\mathrm{p}<0.05$ for all time points).

\section{DISCUSSION}

This is the first study assessing pregnancy and the postpartum course in patients with rheumatoid arthritis and ankylosing spondylitis using a health related quality of life instrument. Our results clearly showed that pregnancy markedly influenced physical functioning even in healthy women, and could also elicit discomfort and pain in the third trimester. By contrast, pregnancy did not impair mental health. None of the women studied developed postpartum depression which occurs in $8-15 \%$ of puerperal women. This
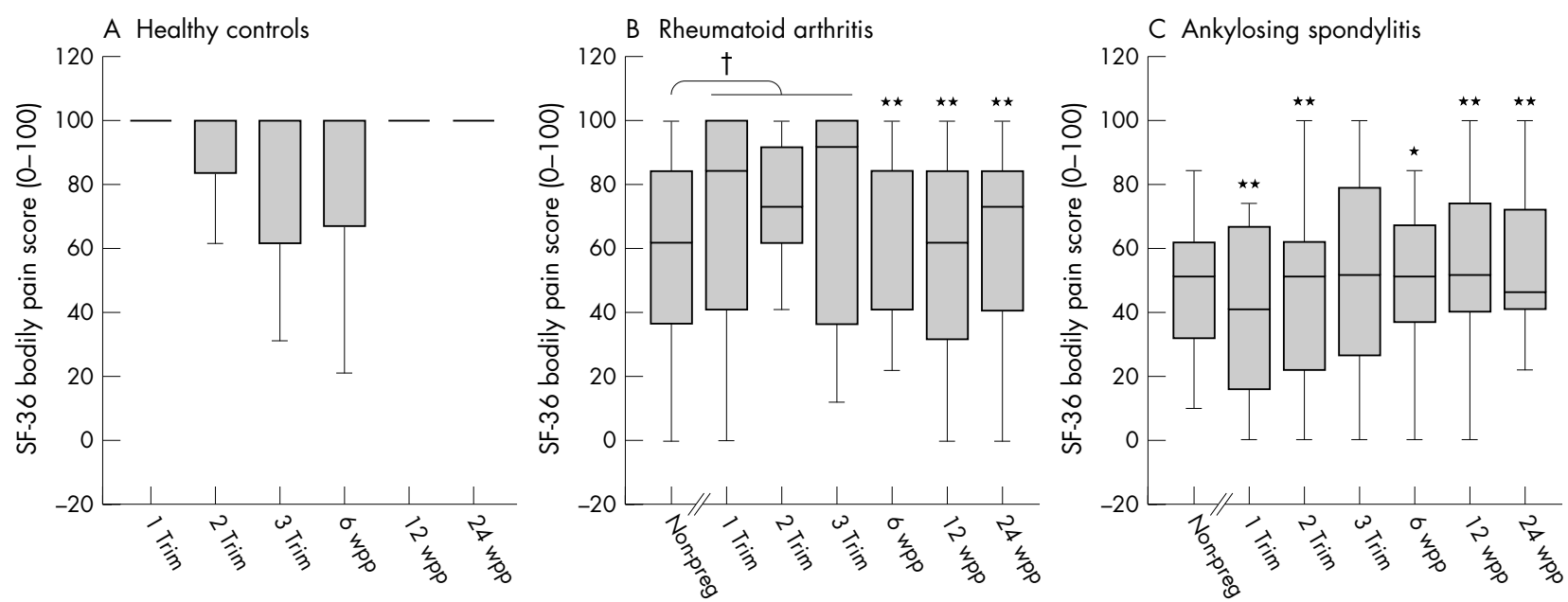

Figure 2 Short form 36 item general health survey (SF-36) bodily pain scores during and after pregnancy in healthy controls (A) and in patients with rheumatoid arthritis (B) and ankylosing spondylitis (C). SF-36 scores range from 0 to $100(0=$ worst score, $100=$ best scores). Boxes represent the 25th and 75th centiles; horizontal lines within boxes represent the medians; vertical lines above and below boxes represent the distribution beyond the 25th to 75 th centile range. ${ }^{*}$ Significant difference from healthy controls at $p<0.01 ;{ }^{*}$ significant difference from healthy controls at $p<0.001 ;$ tsignificant difference between pooled data of pregnant patients and non-pregnant patients; non-preg =non-pregnant controls, 1 trim $=1 \mathrm{st}$ trimester, 2 trim $=2 \mathrm{nd}$ trimester, 3 trim $=3$ rd trimester, $6 \mathrm{wpp}=6$ weeks postpartum, $12 \mathrm{wpp}=12$ weeks postpartum, $24 \mathrm{wpp}=24$ weeks postpartum. 

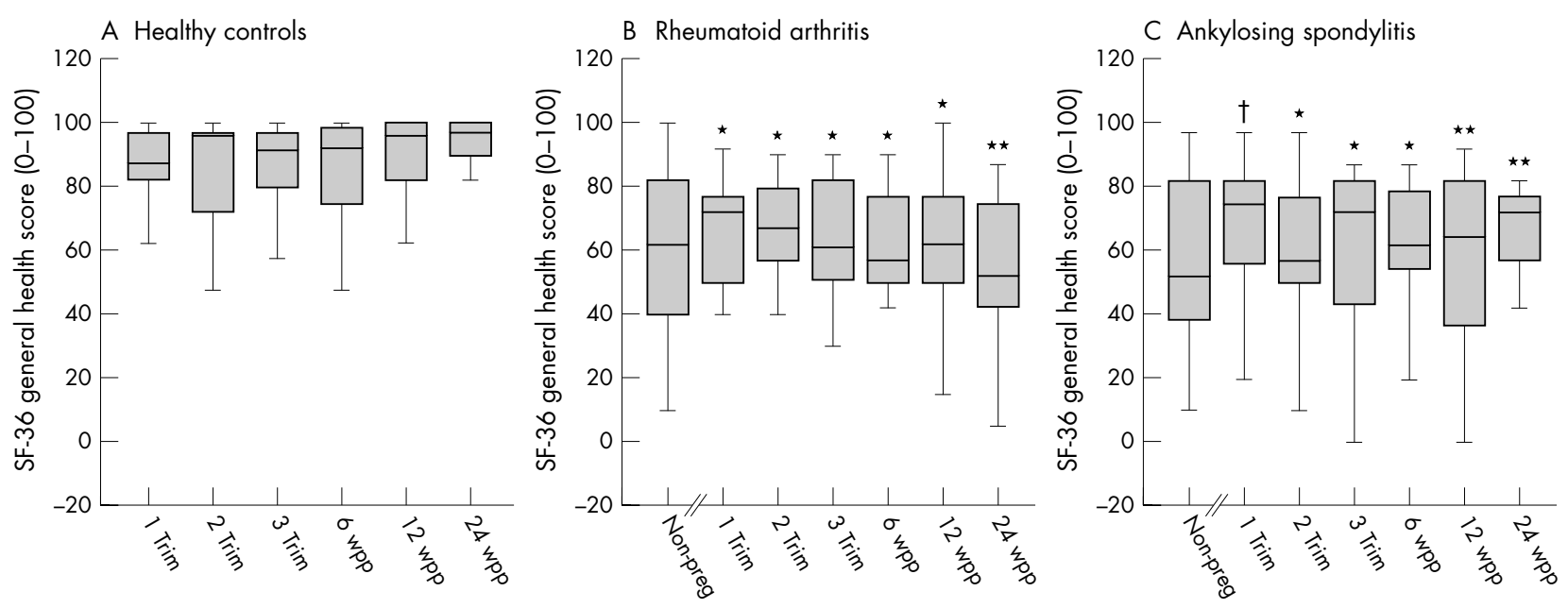

Figure 3 Short form 36 item general health survey (SF-36) general health scores during and after pregnancy in healthy controls (A) and in patients with rheumatoid arthritis (B) and ankylosing spondylitis (C). SF-36 scores range from 0 to $100(0=$ worst score, $100=$ best scores). Boxes represent the 25th and 75th centiles; horizontal lines within boxes represent the medians; vertical lines above and below boxes represent the distribution beyond the 25 th to 75 th centile range. +Significant difference from healthy controls at $p<0.05$; ${ }^{*}$ significant difference from healthy controls at $p<0.01$; ${ }^{* *}$ significant difference from healthy controls at $p<0.001$; non-preg $=$ non-pregnant controls, 1 trim $=1$ st trimester, 2 trim $=2$ nd trimester, 3 trim $=3$ rd trimester, $6 \mathrm{wpp}=6$ weeks postpartum, $12 \mathrm{wpp}=12$ weeks postpartum, $24 \mathrm{wpp}=24$ weeks postpartum.

could have been accidental, but might also relate to living in stable relationships and to the absence of psychosocial stress factors in our cohorts.

In contrast to the limited impact of pregnancy on mental wellbeing, there were great differences in the physical component of the SF-36 in patients and healthy women. The physical impairment in the third trimester was less pronounced in patients with rheumatoid arthritis and ankylosing spondylitis than in healthy controls, and the mental health scores were stable even with persisting active disease during pregnancy or during a postpartum flare. Of the pregnant patients included, most of those with ankylosing spondylitis entered pregnancy with active disease and suffered the greatest impairment of health related quality of life. Our findings that physical scores and bodily pain scores were not altered by pregnancy or the postpartum period are in line with other studies of disease activity in pregnant patients with ankylosing spondylitis. ${ }^{714}$ By contrast, rheumatoid patients experienced an improvement in physical wellbeing and pain during pregnancy, resulting in comparable scores to healthy controls in the second and third trimester. The observed improvement in rheumatoid disease during pregnancy, as well as the postpartum recurrence of the disease, is in agreement with other prospective studies, although the latter did not evaluate mental wellbeing. ${ }^{1}{ }^{15}$

Only two studies have evaluated health related quality of life during pregnancy in healthy women using the SF-36. Our findings of physical impairment during late pregnancy in healthy women are in line with a study investigating 125 healthy white women throughout pregnancy using the SF$36 .^{16}$ Impairment in physical functioning, pain, and role limitation caused by physical problems were observed as pregnancy progressed. However, emotional wellbeing also depends on social status and ethnoracial origin, as shown by a cross sectional study analysing 105 healthy women of AfroAmerican origin in late pregnancy. ${ }^{17}$ Over half of this cohort was categorised as depressed, presenting significantly lower scores in all SF-36 dimensions compared with the nondepressed subjects. The stable mental health status in our patients with rheumatoid arthritis and ankylosing spondylitis could reflect their secure psychosocial background, their wish for children, and the continuous follow up in a specialised pregnancy clinic. Competent care during and after pregnancy helps to diminish anxiety and depression.

By measuring health related quality of life, the SF-36 focuses on both physical and mental wellbeing as perceived by the patient. The question arises over whether the SF-36 is also capable of reflecting disease activity in rheumatoid arthritis and ankylosing spondylitis in a similar way to instruments that include only musculoskeletal symptoms and physical function. Indeed, in two studies of nonpregnant patients with rheumatoid arthritis the SF-36 physical functioning scores correlated significantly with disease activity measured by the arthritis impact measurement scales and the modified health assessment questionnaire. ${ }^{18}{ }^{19}$ Similarly, in a cohort of non-pregnant patients with ankylosing spondylitis a significant correlation of the SF-36 and the BASDAI could be observed ${ }^{20}$ In line with these data, we were able to show a correlation between the SF-36 physical functioning scale and the RADAI and BASDAI in pregnant patients with rheumatoid arthritis and ankylosing spondylitis, respectively. Thus in these two diseases the SF-36 is not only capable of reflecting the individual impact of the disease but also the level of disease activity.

A limitation of our study was the small number of pregnant patients included and the multiple comparisons. Thus significant changes might have been missed. However, by comparing pregnant patients with healthy controls we were able to discriminate disease related changes from pregnancy induced alterations. This differentiation is of particular interest in rheumatic diseases which remain active during pregnancy, such as ankylosing spondylitis, and where symptoms of pregnancy can be confounded with symptom aggravation by disease.

In conclusion, pregnancy reduces physical functioning independent of disease, but not mental or emotional health. This information is helpful when counselling patients who want to have children. In addition, the pregnancy experience documented in our patients may be helpful for other patients contemplating pregnancy.

\section{ACKNOWLEDGEMENTS}

We thank all patients and healthy women who participated in the study. The study was supported by grant 31-59979 from the Swiss National Research Fund, from the Swiss League against 
Rheumatism, from the Klaus and Senta Hermann Foundation, and from an HWP grant of the Technical University of Munich.

\section{Authors' affiliations}

F Förger, M Østensen, P M Villiger, Department of Rheumatology and Clinical Immunology and Allergology, University Hospital, Bern,

Switzerland

A Schumacher, County Hospital of Belp, Switzerland

\section{REFERENCES}

1 Ostensen M, Husby G. A prospective clinical study of the effect of pregnancy on rheumatoid arthritis and ankylosing spondylitis. Arthritis Rheum 1983;26:1155-9.

2 Ostensen $M$, Ostensen $\mathrm{H}$. Ankylosing spondylitis-the female aspect. J Rheumatol 1998;25:120-4.

3 Ostensen $M$. Counselling women with rheumatic disease - how many children are desirable? Scand J Rheumatol 1991;20:121-6.

4 Ware JE, Sherbourne CD. The MOS 36-item short-form health status survey (SF-36). 1. Conceptual framework and item selection. Med Care 1992;30:473-83.

5 McHorney CA, Ware JE, Lu JFR, Sherbourne CD. The MOS 36-item short-form health survey (SF-36): II. Psychometric and clinical tests of validity in measuring physical and mental health constructs. Med Care 1993;31:247-63.

6 McHorney CA, Ware JE, Lu JFR. The MOS 36-item short-form health survey (SF-36). III. Tests of data quality, scaling assumptions and reliability across diverse patient groups. Med Care 1994;32:40-66.

7 Ostensen M, Fuhrer L, Mathieu R, Seitz M, Villiger PM. A prospective study of pregnant patients with rheumatoid arthritis and ankylosing spondylitis using validated clinical instruments. Ann Rheum Dis 2004;63:1212-17.

8 Arnett FC, Edworthy SM, Bloch DA, McShane DJ, Fries JF, Cooper NS, et al. The American Rheumatism Association 1987 revised criteria for the classification of rheumatoid arthritis. Arthritis Rheum 1988;31:315-24.
9 Van der Linden S, Valkenburg HA, Cats A. Evaluation of diagnostic criteria for ankylosing spondylitis: a proposal for modification of the New York criteria. Arthritis Rheum 1984;27:361-8.

10 Stucki G, Liang MH, Stucki S, Bruhlmann P, Michel BA. A self-administered rheumatoid arthritis disease activity index (RADAI) for epidemiological research. Arthritis Rheum 1995;38:795-98.

11 Garrett S, Jenkinson T, Kennedy LG, Whitelock H, Gaisford P, Calin A. A new approach to defining disease status in ankylosing spondylitis: the Bath Ankylosing Spondylitis Disease Activity Index. J Rheumatol 1994;21:2286-91.

12 Bullinger M, Kirchberger I. SF-36 Fragebogen zum Gesundheitszustand. Göttingen: Hogrefe-Verlag, 1998.

13 Ware JE, Snow KK, Kosinski M, Gandek B. SF-36 health survey: manual and interpretation guide. Boston: The Health Institute/New England Medical Center, 1993.

14 Gran JT, Ostensen M. Spondylarthritides in females. Ballieres Clin Rheumatol 1998;12:695-715.

15 Nelson JL, Hughes KA, Smith AG, Nisperos BB, Branchaud AM, Hansen JA. Maternal-fetal disparity in HLA class II alloantigens and the pregnancyinduced amelioration of rheumatoid arthritis. N Engl J Med 1993;329:466-71

16 Hueston WJ, Kasik-Miller S. Changes in functional health status during normal pregnancy. J Fam Pract 1998;47:209-12.

17 McKee MD, Cunningham M, Jankowski KRB, Zayas L. Health-related functional status in pregnancy: relationship to depression and social support in a multi-ethnic population. Obstet Gynecol 2001;97:988-93.

18 Kvien TK, Kaasa S, Smedstad LM. Performance of the Norwegian SF-36 health survey in patients with rheumatoid arthritis. II. A comparison of the SF-36 with disease-specific measures. J Clin Epidemiol 1998;51:1077-86.

19 Talamo J, Frater A, Gallivan S, Xoung A. Use of the short form 36 (SF36) for health status measurement in rheumatoid arthritis. $\mathrm{Br} J$ Rheumatol 1997;36:463-9.

20 Van Tubergen A, Coenen J, Landewe R, Spoorenberg A, Chorus A, Boonen A, et al. Assessment of fatigue in patients with ankylosing spondylitis: a psychometric analysis. Arthritis Rheum 2002;47:8-16.

We are delighted to announce that the Annals of the Rheumatic Diseases launched a "publish ahead of print" programme in February 2004. Selected papers are fast tracked and published online months before they appear in the print journal.

Papers of major significance to the international rheumatology community are published within days of acceptance. The first published article is the raw accepted manuscript; edited and typeset versions are also published as soon as they are available.

In addition to being available on ARD Online, the publish ahead of print articles are searchable through PubMed/ Medline-establishing primacy for your work. They are linked from the ARD Online home page.

To take advantage of this "publish ahead of print" programme submit your papers to the Annals of the Rheumatic Diseases using our online submission and review system Bench > Press (http://submit-ard.bmijournals. com). For further information contact ARD@bmigroup.com. 